\title{
Retweeting Covid-19 disability issues: Risks, support and outrage
}

\author{
Mike Thelwall; Jonathan M. Levitt
}

How to cite this article:

Thelwall, Mike; Levitt, Jonathan M. (2020). "Retweeting Covid-19 disability issues: Risks, support and outrage". El profesional de la información, v. 29, n. 2, e290216.

https://doi.org/10.3145/epi.2020.mar.16

Manuscript received on $8^{\text {th }}$ April 2020 Accepted on $14^{\text {th }}$ April 2020

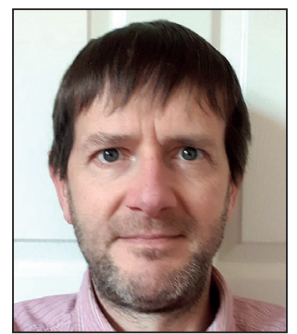

Mike Thelwall $\square$

https://orcid.org/0000-0001-6065-205X

University of Wolverhampton

Statistical Cybermetrics Research Group

Wulfruna Street

Wolverhampton WV1 1LY, UK

M.Thelwall@wlv.ac.uk

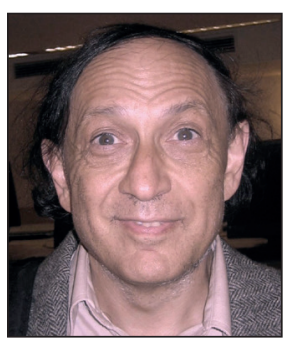

Jonathan M. Levitt

https://orcid.org/0000-0002-4386-3813

University of Wolverhampton

Statistical Cybermetrics Research Group

Wulfruna Street

Wolverhampton WV1 1LY, UK

J.M.Levitt@w/v.ac.uk

\begin{abstract}
The Covid-19 pandemic has greatly uneven impacts on sectors of society. People with disabilities are particularly vulnerable to it and so it is important to understand both the disability perspective and the role of social media. This information may help to reduce the risk from the disease. In response, this article uses thematic analysis to investigate 59 disability-related tweets from March 10 to April 4, 2020 that were retweeted at least 500 times, with a quarter of a million retweets altogether. This approach generates quick insights into widely resonating disability-related issues. The results suggest the value of Twitter for disseminating information about the risk, offers or requests for support, the ability of many people with disabilities to adjust to the changes well, and information about individuals with the disease. In addition, there was outrage at suggestions that the disease was less serious because young people without disabilities were relatively low risk, and that people with disabilities might be denied equal access to medical treatment. As one tweet pointed out, people in less vulnerable categories should not be told on Twitter or elsewhere that the disease is less relevant to them because their actions can impact others through social spreading.
\end{abstract}

\section{Keywords}

Covid-19; Coronavirus; Disability; Twitter; Social media; Social networks; Retweeting; People with disabilities; Disabled people; Health information; Pandemics; Thematic analysis.

\section{Introduction}

The Covid-19 outbreak was declared a "Public Health Emergency of International Concern" by the World Health Organisation (WHO) on 30 January 2020 (WHO, 2020a) and a pandemic on 11 March 2020 (WHO, 2020b). On 26 March, WHO released a 13-page document summarising disability-related considerations, stating that people with disabilities were at higher risk. This document also specified protective measures could reduce this additional risk (WHO, 2020c). These measures include protective steps for people with disabilities, such as planning for the effects of social isolation measures. The document also includes recommendations for governments, such as the need to plan to ensure the continuation of services for disabled people. Given the lethality of the disease and the extra vulnerability of many people with disabilities, it is important to assess their reactions and identify the issues considered to be most important. In addition, since public health communication is vital to preventing the spread of the disease, it is also useful to understand the role of social media.

This article uses retweeting as an indicator of interest in a topic. Twitter is a common source of news (Tandoc; Johnson, 2016), information and personal sharing (Boyd; Golder; Lotan, 2010). If a tweet is retweeted many times, then it has probably resonated on a large scale. Depending on the content of the tweet, this might reflect agreement with its content, a desire to be visible in a debate, or a need to interact with others (Boyd; Golder; Lotan, 2010). An individual tweet is more likely to be retweeted if the tweeter has many social connections on the site (Suh; Hong; Pirolli; Chi, 2010; cf. Lachlan; Xu; Hutter; Adam; Spence, 2019) and therefore some potentially important tweets about any topic get overlooked because they originate with less well connected people. 
Social media have the potential to support many useful activities for people with disabilities, including social and informational (Caton; Chapman, 2016; Ellis; Kent, 2016; McNeil; Brna; Gordon, 2012). Interpersonal interactions on the social web can help people with disabilities to form identities and communities through connections with likeminded others (Miller, 2017; Sweet; LeBlanc; Stough; Sweany, 2020), to gain support against bullying (Sweet; LeBlanc; Stough; Sweany, 2020) and publish their own self-descriptions and narratives (Gale; Bolzan, 2016). This can extend to online activism, coordinating and publicising through social media sites (Pearson; Trevisan, 2015) and blogs (Trevisan, 2017). One of the functions of personal stories can be to publicly challenge stereotypes and hidden discrimination (Cocq; Ljuslinder, 2020). This perhaps reflects a more general tendency for interest groups to routinely exploit social media (Scaramuzzino; Scaramuzzino, 2017). Thus, the social web seems to be a valuable space for people with disabilities, despite its occasional use for cyberbullying and hate speech (Kowalski; Toth, 2018).

This article addresses the need to gain insights into the perspective of people with disabilities in relation to Covid-19 and the need to understand the role of social media, and Twitter in particular. It uses a qualitative fast reaction method: a thematic analysis of highly retweeted tweets about Covid-19-related disability issues. A quick method is needed so that the results can be published in time to inform the reaction to the pandemic. This method exploits the free availability of tweets and the widespread use of Twitter in many countries to discuss news-related topics.

\section{Methods}

Tweets about Covid-19 in English were collected from the Twitter applications programming interface (API) using the queries Covid-19, coronavirus, and "corona virus" from March 10 to April 6, 2020. Initial pilot testing on March 10 had found these three to be the main ways in which the illness was mentioned on Twitter.

The tweets downloaded were processed to identify those about disability by selecting those containing the text segments, "disab", "ableism", "ableist", "pwd" (people with disabilities). These segments were identified by browsing tweets containing the terms disabled or disability. These text segments occur in all variations of the word disability (e.g., disabled, disabilities) and match words as well as hashtags. This produced a set of disability-related Covid-19 tweets accounting for $0.1 \%$ of the unique $4,122,227$ tweets (after eliminating duplicate tweets, such as retweets of the same original tweet, and near duplicates, which are two tweets that are identical except for hashtags and @ usernames) extracted from the original set of 9,431,367 downloaded. Only tweets in English were analysed to give a coherent set. Disability-specific terms, such as wheelchair-user or visually impaired, were not included to allow the focus to be on the broad perspective.

Retweeted tweets were extracted from the disability-related Covid-19 tweets when the retweet count was above 500 . This minimum was chosen heuristically to allow a moderate number of tweets to be analysed. This produced 66 tweets, but seven were manually filtered out for being irrelevant (e.g., about disabling software).

The 59 highly retweeted disability tweets were analysed using thematic analysis (Braun; Clarke, 2006). This qualitative method is appropriate because it is exploratory and so can be applied to new contexts without prior expectations about the outcomes. Since Covid-19 has recently emerged, there is no disability research about it from which to form prior expectations and so an exploratory method is appropriate. Thematic analysis is suitable because it is not theory driven and therefore fits the exploratory goals better than other approaches, such as grounded theory.
Table 1. The number of unique tweets per day matching the Twitter API queries Covid-19, coronavirus, or "corona virus" ( $n=9,431,367$ originally downloaded), and the disability subset containing the text segments, "disab", "ableism", "ableist", or "pwd”. March 10 and April 6 were partial days and data collection was slower 22-24 March for technical reasons.

\begin{tabular}{|c|c|c|}
\hline Date & Tweets & Disability tweets \\
\hline 10 March 2020 & 44,241 & 44 \\
\hline 11 March 2020 & 148,525 & 122 \\
\hline 12 March 2020 & 144,402 & 118 \\
\hline 13 March 2020 & 156,701 & 132 \\
\hline 14 March 2020 & 127,889 & 95 \\
\hline 15 March 2020 & 129,645 & 103 \\
\hline 16 March 2020 & 149,953 & 145 \\
\hline 17 March 2020 & 143,813 & 135 \\
\hline 18 March 2020 & 146,550 & 153 \\
\hline 19 March 2020 & 161,002 & 153 \\
\hline 20 March 2020 & 140,329 & 153 \\
\hline 21 March 2020 & 124,028 & 135 \\
\hline 22 March 2020 & 85,031 & 83 \\
\hline 23 March 2020 & 50,467 & 53 \\
\hline 24 March 2020 & 195,237 & 299 \\
\hline 25 March 2020 & 318,829 & 371 \\
\hline 26 March 2020 & 249,173 & 355 \\
\hline 27 March 2020 & 228,147 & 257 \\
\hline 28 March 2020 & 174,875 & 214 \\
\hline 29 March 2020 & 159,219 & 178 \\
\hline 30 March 2020 & 162,861 & 206 \\
\hline 31 March 2020 & 158,299 & 188 \\
\hline 01 April 2020 & 150,989 & 177 \\
\hline 02 April 2020 & 136,893 & 149 \\
\hline 03 April 2020 & 137,140 & 173 \\
\hline 04 April 2020 & 110,043 & 101 \\
\hline 05 April 2020 & 103,043 & 99 \\
\hline 06 April 2020 & 84,903 & 110 \\
\hline Total & $4,122,227$ & 4,501 \\
\hline
\end{tabular}


For the thematic analysis, the first author read all the tweets twice, including on Twitter.com to see any associated pictures or links, and assigned them initial codes reflecting their main contents. The tweets were then re-coded after reflecting on the initial codes. The tweets were then clustered by theme and recoded three times, adjusting the codes to make them more uniform and generalised to allow similar tweets to fit within common themes as much as possible. In some cases, disability was mentioned in a tweet alongside other factors, such as age, but in all cases disability was judged to be a core part of the tweet so no tweets were rejected on the basis of limited relevance. Although thematic analysis usually involves multiple coders, as a fast reaction article only a single coder was used (the first author). The themes are reported in the Results section.

\section{Ethics}

The topic of this study raises potential ethical issues. Nevertheless, although there is no consensus on internet-based ethics (Golder; Ahmed; Norman; Booth, 2017), the current study was exempt from formal ethical approval due to only analysing fully public online texts. Following best practice (Wilkinson; Thelwall, 2011), the anonymity of all tweeters was preserved in this paper by not including any names or exact quotes. Exceptions were made only for tweets from prominent political figures (Barak Obama, António Guterres), a large official organisation (WHO) and a large media source (ABC, Australian Broadcasting Corporation).

\section{Results}

The data collection phrase identified 285,471 retweets from 59 tweets with at least 500 retweets each, excluding irrelevant matches. The following main themes were identified, listed in decreasing order of the total number of retweets. As mentioned above, for ethical reasons, only high-profile tweeters are quoted. Because this is a qualitative study, the results are reported as a list rather than a table but associated quantitative information is also given for each theme. The number of tweets from people declaring disabilities is also reported, based on the tweeter's profile and a Google search for them. The total includes carers of disabled children and people that describe themselves as disability activists.

3.1. Support for people with disabilities (19 tweets, including 8 from people declaring disabilities, 172,139 retweets, min 510 retweets, max 128,125 retweets):

Many tweets mentioned support given to people with disabilities in response to Covid-19, including individual offers of, or requests for, shopping help, and shop opening hours for people with disabilities ("A supermarket chain in Australia opened earlier than usual, giving the elderly and disabled a dedicated hour to shop amid the coronavirus pandemic, before stores opened to the general public."), and the elderly (Figure 1). Four of these tweets mentioned that some of the facilities offered were needed before Covid-19 by disabled people (such as remote working or studying) and the new situation showed that the facilities had previously been possible but denied.

\subsection{People with disabilities are more likely to} be denied Covid-19 treatment ( 9 tweets, including 8 from people declaring disabilities, 34,366 retweets, min 754 retweets, $\max 11,849$ retweets):

Suggestions that people with disabilities might be given lower priority for Covid-19 treatment (along with the elderly and some other groups) attracted several outraged tweets and at there was at least one policy change in response to the general outrage (the UK NHS: Mencap, 2020) (figure 2).

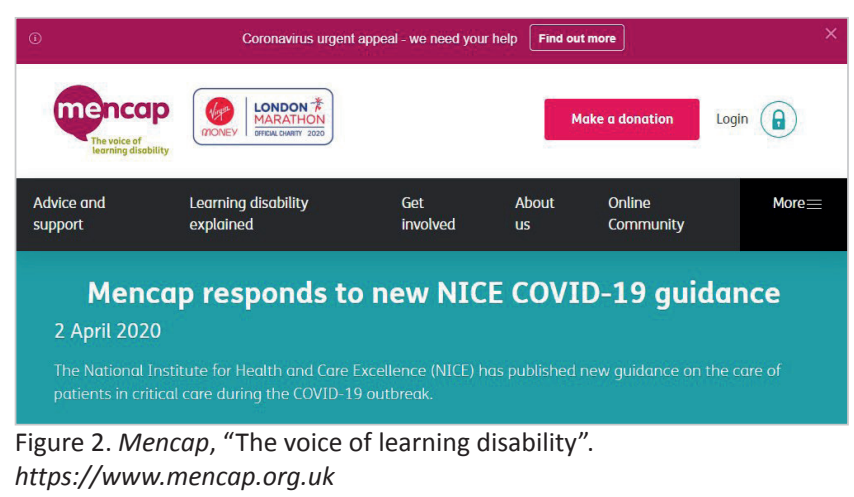

3.3. Don't treat people with disabilities as disposable casualties ( 9 tweets, including 5 from people declaring disabilities, 32,454 retweets, min 516 retweets, $\max 18,243$ retweets):

News stories and tweets telling the population not to worry too much because Covid-19 was the greatest threat to the elderly and people with long term conditions triggered outraged responses on Twitter. These tweets emphasised that all casualties are equally tragic. 


\subsection{People with disabilities are used to dealing with commu-} nication disruption (3 tweets, none from people declaring disabilities, 15,173 retweets, min 1,007 retweets, max 8,498 retweets):

Two tweets mentioned that some able-bodied people were complaining about the difficulty in using remote communication technologies, which people with disabilities had been doing for a long time. Another tweet praised the mutual support offered by disabled groups, holding it as an example for others ("And @cripchick, a disabled activist, understands what it's like for people with particular vulnerabilities to come together for support:").

\subsection{Covid-19 is a greater risk to people with disabilities (6} tweets, including 3 from people declaring disabilities, 7,016 retweets, min 563 retweets, $\max 2,543$ retweets):

Some official World Health Organisation and other tweets warned that people with disabilities were more at risk from Covid-19 than the general population, giving reasons or suggesting actions (e.g., "NEW WHO guidance on disability during \#COVID19. Populations with \#disability may be impacted more significantly by \#coronavirus. This can be mitigated if simple actions \& protective measures are taken" (Figure 4). Retweeting these would be primarily informational, presumably serving as a warning to people with disabilities, and others that might need to change their actions in response (e.g., carers, health professionals, policy makers).

3.6. People with Covid-19 (4 tweets, none from people declaring disabilities, 6,572 retweets, min 588 retweets, max 4,492 retweets):

Three tweets reported stories of people with disabilities that had died due to Covid-19 to remember them or to warn of the need for social isolation.

\subsection{People with disabilities should not be overlooked when} planning ( 3 tweets, including 2 from people declaring disabilities, 4,174 retweets, min 645 retweets, max 2,842 retweets):

Some legislation or strategies related to Covid-19 overlooked the situation for people with disabilities and this was pointed out on Twitter ("People with disabilities should not be left behind in the fight against the \#COVID19 pandemic. We must listen to their concerns and provide them, and their caregivers, with the appropriate support." (Figure 5 ).

3.8. Other ( 6 tweets, none from people declaring disabilities, 13,847 retweets, min 1,007 retweets, max 7,825 retweets):

Other topics included criticizing Donald Trump for mocking people with disabilities, a disabled person being evicted for housing redevelopment, and law change to help people disabled by Covid-19.

\section{Discussion}

The results have several limitations. They are subjective to the coder (first author) and limited in breadth because there may be important topics that were discussed in other places, such as WhatsApp, Facebook, or mainstream news sources. More personal topics would presumably be discussed in private environments and some people with disabilities may prefer to avoid Twitter. There may also be issues widely discussed on Twitter without a single highly retweeted tweet. Misinformation may be largely missing from the collection due to efforts by Twitter to combat it (BBC, 2020).

The themes generated from the retweets do not seem surprising in the sense that they largely echo, but in a stronger form, many ongoing concerns of people with disabilities. The topics also reflect press coverage of Covid-19 to some extent, but also include reac-

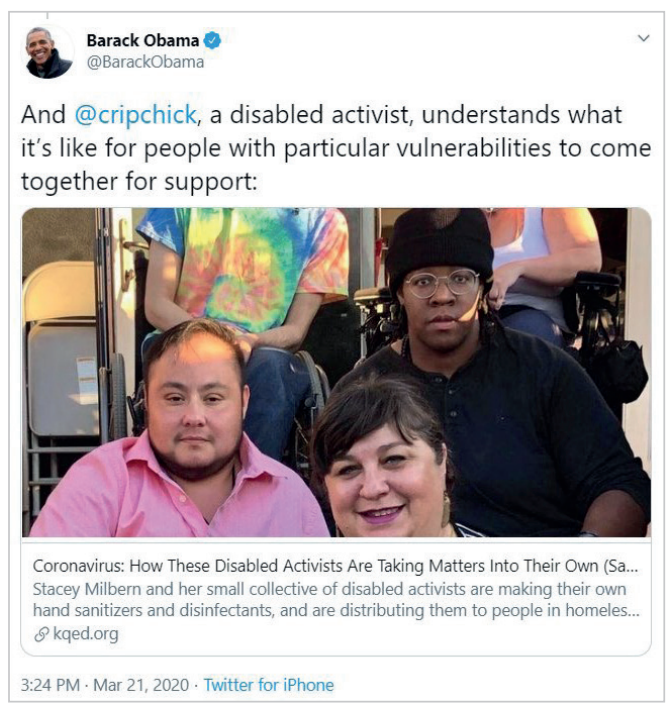

Figure 3. A Barack Obama tweet praised the mutual support offered by disabled groups.

https://twitter.com/BarackObama/status/1241354900677832709

World Health Organization (WHO) @WHO

NEW WHO guidance on disability during \#COVID19. Populations with \#disability may be impacted more significantly by \#coronavirus. This can be mitigated if simple actions \& protective measures are taken - bit.ly/33ZDtKo

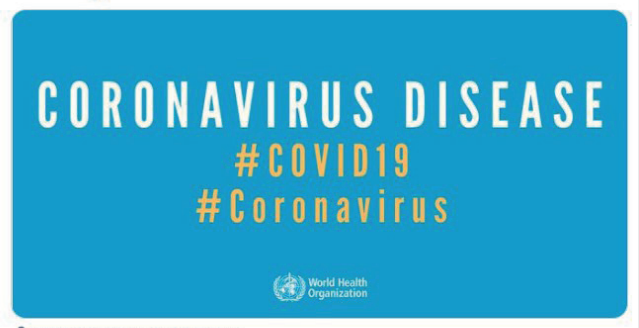

United Nations and 9 others

3:01 PM · Apr 3, 2020 - Twitter Web App

Figure 4. New WHO guidance on disability during \#Covid19. Populations with \#disability may be impacted more significantly by \#coronavirus.

https://twitter.com/WHO/status/1246045067560837122

António Guterres

People with disabilities should not be left behind in the fight against the \#COVID19 pandemic.

We must listen to their concerns and provide them, and their caregivers, with the appropriate support.

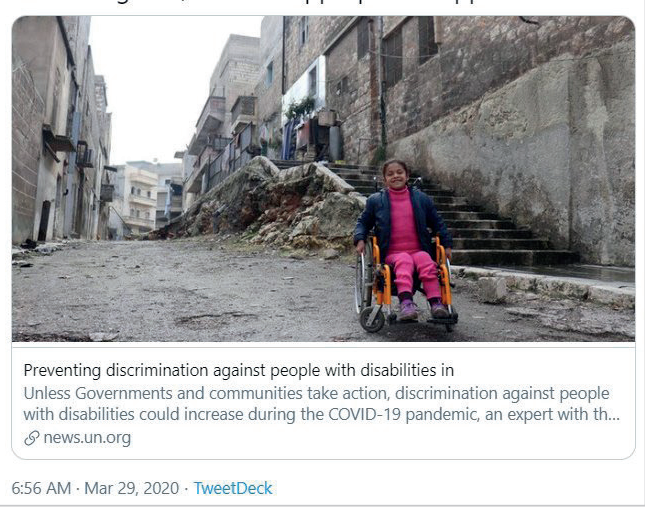

Figure 5. António Guterres: "People with disabilities should not be left behind in the fight against the \#Covid19 pandemic". https://twitter.com/antonioguterres/status/1244111036325732353 
tions mainly from people with disabilities, emphasising that second class treatment would not be passively accepted. This continues a tradition of social media use for disability-related activism (Pearson; Trevisan, 2015).

In terms of the useful information retweeted, this is a positive role for Twitter. A retweet does not guarantee that the information was used because behaviour change is a complex process (Cugelman; Thelwall; Dawes, 2011). Nevertheless, there is some connection between health-related information on Twitter and general awareness of health information (Farhadloo; Winneg; Chan; Jamieson; Albarracin, 2018). Thus, it seems likely that the information will have successfully informed and reminded some people, helping them plan and isolate effectively.

One interesting phenomena in comparison to other analyses of serious issues is that none of the highly retweeted tweets were jokes. Humour is common on Twitter, helping to drive retweeting (Majmundar; Allem; Boley-Cruz; Unger, 2018), and is also a strategy used by people with disability to discuss their conditions (Milbrodt, 2018). Thus, on Twitter, disability issues for Covid-19 seem to be taken so seriously that all messages were straightforward. This might be due to a combination of the potential for misunderstanding and the seriousness of the situation. A second, and welcome, absence was of anti-disability content. No highly retweeted tweets denigrated people with disabilities or argued that others should have priority for medical or other support.

\section{Conclusions}

The results confirm that Covid-19 is perceived as a major threat to people with disabilities on Twitter. The site seems to have been useful to share basic information about the disease, including information about, or requests for, support for people with disabilities. These are valuable informational roles and underline that social media should be taken into account within public health campaigns. The tweets expressing dismay about the low priority sometimes given to disability issues to people with disabilities for medical treatment confirm the importance of these issues. Making feelings known about this on Twitter and elsewhere may have been important in getting policy changes in response and ensuring that the issue is not forgotten, although there is no concrete evidence of this. Thus, overall, Twitter seems to be a valuable part of the information and political ecosystem for Covid-19.

\section{Bibliography}

BBC (2020). Coronavirus: Fake news crackdown by UK government.

https://www.bbc.co.uk/news/technology-52086284

Boyd, Danah; Golder, Scott; Lotan, Gilad (2010). "Tweet, tweet, retweet: Conversational aspects of retweeting on Twitter". In: $201043^{\text {rd }}$ Hawaii international conference on system sciences (pp. 1-10). Los Alamitos, CA: IEEE Press.

https://doi.org/10.1109/HICSS.2010.412

Braun, Virginia; Clarke, Victoria (2006). "Using thematic analysis in psychology". Qualitative research in psychology, v. 3, n. 2, pp. 77-101.

https://doi.org/10.1191/1478088706qp063oa

Caton, Sue; Chapman, Melanie (2016). "The use of social media and people with intellectual disability: A systematic review and thematic analysis". Journal of intellectual and developmental disability, v. 41, n. 2, pp. 125-139.

https://doi.org/10.3109/13668250.2016.1153052

Cocq, Coppélie; Ljuslinder, Karin (2020). "Self-representations on social media. Reproducing and challenging discourses on disability". Alter (in press).

https://doi.org/10.1016/j.alter.2020.02.001

Cugelman, Brian; Thelwall, Mike; Dawes, Phil (2011). “Online interventions for social marketing health behavior change campaigns: a meta-analysis of psychological architectures and adherence factors". Journal of medical internet research, v. 13, n. 1 , e17.

https://doi.org/10.2196/jmir.1367

Ellis, Katie; Kent, Mike (eds.). (2016). Disability and social media: Global perspectives. Oxford, UK: Taylor \& Francis. ISBN: 9781472458452

Farhadloo, Mohsen; Winneg, Kenneth; Chan, Man-Pui-Sally; Jamieson, Kathleen-Hall; Albarracin, Dolores (2018). “Associations of topics of discussion on Twitter with survey measures of attitudes, knowledge, and behaviors related to Zika: probabilistic study in the United States". JMIR Public health and surveillance, v. 4, n. 1, e16.

http://doi.org/10.2196/publichealth.8186

Gale, Fran; Bolzan, Natalie (2016). “Online ghettoes, perils or supernannies? Australian young people with chronic illness and disability challenge some moral panics about young people online". Disability \& society, v. 31, n. 8, pp. 1112-1126.

https://doi.org/10.1080/09687599.2016.1236717 
Golder, Su; Ahmed, Shahd; Norman, Gill; Booth, Andrew (2017). "Attitudes toward the ethics of research using social media: a systematic review". Journal of medical internet research, v. 19, n. 6, e195. https://doi.org/10.2196/jmir.7082

Kowalski, Robin M.; Toth, Allison (2018). "Cyberbullying among youth with and without disabilities". Journal of child \& adolescent trauma, v. 11, n. 1, pp. 7-15.

https://doi.org/10.1007/s40653-017-0139-y

Lachlan, Kenneth A.; Xu, Zhan; Hutter, Emily E.; Adam, Rainear; Spence, Patric R. (2019). "A little goes a long way: serial transmission of Twitter content associated with Hurricane Irma and implications for crisis communication". Journal of strategic innovation and sustainability, v. 14, n. 1, pp. 16-26.

https://doi.org/10.33423/jsis.v14i1.984

Majmundar, Anuja; Allem, Jon-Patrick; Boley-Cruz, Tess; Unger, Jennifer-Beth (2018). "The why we retweet scale". PloS one, v. 13, n. 10, e0206076.

https://doi.org/10.1371/journal.pone.0206076

McNeil, Karen; Brna, Paula M.; Gordon, Kevin E. (2012). "Epilepsy in the Twitter era: a need to re-tweet the way we think about seizures". Epilepsy \& behavior, v. 23, n. 2, pp. 127-130.

https://doi.org/10.1016/j.yebeh.2011.10.020

Mencap (2020). Mencap responds to revised critical care guidance from NICE (2 April update).

https://www.mencap.org.uk/press-release/mencap-responds-deeply-troubling-new-nice-covid-19-guidance

Milbrodt, Teresa (2018). "Today I had an eye appointment, and I'm still blind: Crip humor, storytelling, and narrative positioning of the disabled self". Disability studies quarterly, v. 38, n. 2.

https://dsq-sds.org/article/view/6163

Miller, Ryan A. (2017). "My voice is definitely strongest in online communities: Students using social media for queer and disability identity-making". Journal of college student development, v. 58, n. 4, pp. 509-525.

https://muse.jhu.edu/article/663305

Pearson, Charlotte; Trevisan, Filippo (2015). "Disability activism in the new media ecology: Campaigning strategies in the digital era". Disability \& society, v. 30, n. 6, pp. 924-940.

https://doi.org/10.1080/09687599.2015.1051516

Scaramuzzino, Gabriella; Scaramuzzino, Roberto (2017). "The weapon of a new generation? - Swedish civil society organizations' use of social media to influence politics". Journal of information technology \& politics, v. 14, n. 1, pp. 46-61. https://doi.org/10.1080/19331681.2016.1276501

Suh, Bongwon; Hong, Lichan; Pirolli, Peter; Chi, Ed H. (2010). "Want to be retweeted? large scale analytics on factors impacting retweet in Twitter network". In: 2010 IEEE Second international conference on social computing (pp. 177-184). Menlo Park, CA: IEEE Press.

http://citeseerx.ist.psu.edu/viewdoc/download?doi=10.1.1.367.8218\&rep=rep1\&type=pdf

https://doi.org/10.1109/SocialCom.2010.33

Sweet, Kayla S.; LeBlanc, Jennifer K.; Stough, Laura M.; Sweany, Noelle W. (2020). “Community building and knowledge sharing by individuals with disabilities using social media". Journal of computer assisted learning, v. 36, n. 1, pp. 1-11. https://doi.org/10.1111/jcal.12377

Tandoc Jr, Edson C.; Johnson, Erika (2016). "Most students get breaking news first from Twitter". Newspaper research journal, v. 37, n. 2, pp. 153-166.

http://doi.org/10.1177/0739532916648961

Trevisan, Filippo (2017). "Crowd-sourced advocacy: promoting disability rights through online storytelling". Public relations inquiry, v. 6, n. 2, pp. 191-208.

https://doi.org/10.1177/2046147X17697785

WHO (2020a). 2019-nCoV outbreak is an emergency of international concern.

https://bit.ly/3eoq9Us

WHO (2020b). WHO Director-General's opening remarks at the media briefing on COVID-19, 11 March 2020.

https://bit.ly/2VvgOwy

WHO (2020c). Disability considerations during the COVID-19 outbreak.

https://www.who.int/who-documents-detail/disability-considerations-during-the-covid-19-outbreak

Wilkinson, David; Thelwall, Mike (2011). "Researching personal information on the public Web: Methods and ethics". Social science computer review, v. 29, n. 4, pp. 387-401.

https://doi.org/10.1177/0894439310378979 